\title{
Determinants of Unemployment in Bahrain
}

\author{
Sara Ebrahim Alrayes \\ MBA Student, MBA Program Directorate \\ Collage of Business and Finance \\ Ahlia University \\ Manama, Kingdom of Bahrain \\ Rami Mohammad Abu Wadi \\ Accounting and Economics Department \\ College of Business and Finance \\ Ahlia University \\ Manama, Kingdom of Bahrain
}

\begin{abstract}
This study was conducted to find out the determinants of unemployment in Bahrain. The objectives of the study were to find out the way in which the Gross Domestic Product (GDP), Inflation, Government Expenditure, and Gross Rate of Fixed Capital Formation affects unemployment and to make up policy recommendations from the finding of the study. The study used time series analysis from the year 1980 to 2015. The study found that there is no significant impact of economic growth and inflation on unemployment in Bahrain while there is a significant impact of fixed capital formation and government expenditures on unemployment in Bahrain. The recommendations of the study are that the government should pursue policies that promote economic growth, Gross Rate of Fixed Capital Formation, and carefully and empirically assessed public spending.
\end{abstract}

Keywords: Unemployment, Gross Domestic Product, Government Expenditure, Fixed Capital Formation, Bahrain.

\section{Introduction}

Bahrain has over time experienced a growing number of its population being unemployed (The World Bank, 2016). From the data got from the World Bank website, the following trend line shows the patterns of unemployment in Bahrain since the year 1980 to 2015.

Figure 1: Bahrain Unemployment Rate (1980-2015)

\section{unemployment}

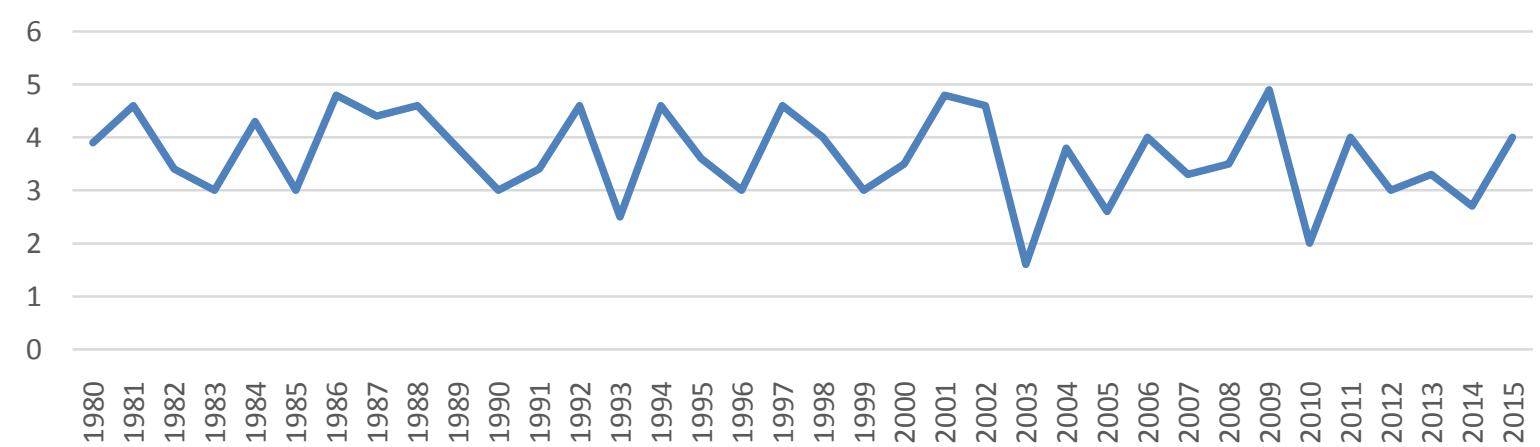

Source: World Bank Country Data (2016) 
The trend line above shows the unemployment trend in Bahrain for the year 1980 to 2015. From the trend line, it can be seen that in the early 2000, unemployment rate was declining. However, around 2005, it shot up, then down toward 2006, and then shot up for the first time high during the period of the study to about 5.6 percent. It has since declined but has been oscillating as shown by the spikes. The study seeks to find out possible factors that could cause these movements in the unemployment rates in Bahrain.

\subsection{Research Problem}

Unemployment in Bahrain has over time been at low rates even though it has been fluctuating. Several studies have looked into the possible factors affecting unemployment in Bahrain (Boyce, Wood, \& Brown, 2012; Bogdan, 2014). Among the leading factors that different studies have fronted by these studies are the education level, economic growth, openness of the economy to trade with external markets, and the level of technology in the country. This study appreciates the findings of these studies but will use a mixed approach to bring forth the macro and microeconomic variables in understanding the unemployment issue in Bahrain. The mixed approach will entail reliance on both secondary time series data and primary time series data. This will enable incorporation of micro foundations into the study. The current study attempts to answer the general research question "What are the factors that impact the Unemployment in Bahrain?" To answer this question the researcher will address the following sub-questions:

1. Does the economic growth have an impact on unemployment in Bahrain?

2. Does the fixed capital formation have an impact on unemployment in Bahrain?

3. Does the total government expenditure have an impact on unemployment in Bahrain?

4. Does the inflation have an impact on unemployment in Bahrain?

\subsection{Research Hypotheses}

The study hypotheses are based on the research objectives. The null and the alternative hypotheses of the research are specified as follows:

$\mathbf{H}_{01}$ : There is no significant impact of economic growth on unemployment in Bahrain.

$\mathbf{H}_{\mathbf{0 2}}$ :There is no significant impact of fixed capital formation on unemployment in Bahrain.

$\mathbf{H}_{03}$ :There is no significant impact of total government expenditures on unemployment in Bahrain.

$\mathbf{H}_{\mathbf{0 4}}$ : There is no significant impact of inflation on unemployment in Bahrain.

\section{Literature Review}

Unemployment refers to the state in the economy in which there are resources that are not engaged in the country's productive activities or when they are under-engaged. Bahrain has over time experienced challenges in employment (Vedder \& Gallaway, 2011). Despite the challenging external and internal environments, Bahrain has maintained economic resilience and continues to be a regional leader in economic freedom (Schoeman, 2014). It remains a financial hub for dynamic economic activity, with high levels of trade and investment bolstered by a competitive and efficient regulatory environment. The kingdom's challenging transition to greater openness, diversification, and modernization continues. Firmly institutionalizing the rule of law by ensuring judicial independence and transparency will be critical to stamping out lingering corruption and safeguarding stability (Valadkhani, 2012). Youth unemployment remains a major long-term economic challenge. This section comprises empirical literature which informed the choice of the study gap and problem.

\subsection{Determinants of Unemployment in Bahrain}

There are a number of factors that are expected to affect unemployment in Bahrain. These include economic growth, total investment, total government expenditure, and inflation.

\subsubsection{Economic Growth and Unemployment}

The Gross Domestic Product of a country refers to the money value of all the goods and services produced within the geographical boundaries of an economic area over a given period of time (Herbener, 2011). From the theory of labor, labor demand is a derived demand. This implies that the demand for labor as a production input depends on the level of economic activity of the country (Herbener, 2011).

When the national income increases, firms respond by increasing the supply of goods and services to reap from the income rise and the increased purchasing potential. As this happens, more labor units are demanded so as to take part in the production of the increased product demands. 
Thus, at any given time, it is expected that when the GDP of a country increases, more employment opportunities are created. Thus, GDP and unemployment are negatively related (Herbener, 2011). The implications of this relationship for policy is that countries that would want to dress the unemployment challenge must target GDP grow policies as well. By pursuing policies that affect GDP, the country is in essence pursuing the unemployment challenge (Herbener, 2011). As the economy undergoes growth, more job opportunities are created and people get employed to take part in the production of the output demand. Thus, economic growth, methinks, is a determinant of unemployment.

\subsubsection{Fixed Capital Formation and Unemployment}

Fixed capital formation refers to the rate at which the capital stock of an economy is rising or declining over time. Capital stock refers to the plant, property, equipment used in undertaking the productive works of the economy. It also comprises the growth of the social and physical infrastructure such as roads and electricity supply over time (Forder, 2010). From one period to the next, firms experience changing capital stocks and this is essential in determining the rates of employment in a country. Often, capital formation is a function of the capital stock of the previous years and an increase in the new stock (Forder, 2010). This is expressed as follows.

$$
k_{t}=k_{t+1}+\Delta i_{t}
$$

In the expression, $k_{t}$ is the capital stock in the current period and it is expressed as a sum of the previous period's capital stock $\left(k_{t+1}\right)$ and the addition to the capital stock in the current year, $\Delta i_{t}$. The $\Delta i_{t}$ can be negative, positive, or zero (Forder, 2010). The changes in capital stock over a given period can be due to depreciation of the existing capital stock, disposals of existing stock, and replenishments of stock. Thus, the rate of capital formation differs from the previous period's stocks by the net change in capital stock (Forder, 2010).

Positive changes in the capital stock are good for the economy since capital is an essential input component in production. However, the positivity of the contribution to employment would depend on a number of things (Forder, 2010). This is because it would depend on the stage of production of the firm. At low levels of capital stock, an additional unit of capital stock to the existing stock would generate higher productivity than at higher levels of capital (Forder, 2010).

Methinks the returns to capital would vary depending on the sector of the economy. However, holding all these factors constant, a quick rate of capital formation is good for the economy because it engages more labor and thus increase it would decrease unemployment.

\subsubsection{Inflation and Unemployment}

Inflation and unemployment from economic theory (Phillip's Curve) are inversely related. This implies that as inflation increase, unemployment decreases but in the short run (Gordon, 2011). The idea behind the inverse relationship between unemployment and inflation is that as unemployment decreases (employment increases), households get higher wage incomes and thus they realize an increase in their purchasing power (Gordon, 2011). As this happens, the aggregate demand for goods and services increase and this pushes up the prices of goods and services. For policy, the implication of this relationship is that some level of inflation is a must. In the long run however, the two variables are not related (Gordon, 2011).

Methinks inflation must exist at any one time. However, there are high levels of it that can make job creation possible because it will affect he aggregate demand and, as this happens, employers will cut down on employment.

\subsubsection{Government Expenditure and Unemployment}

Government expenditure refers to the total expenditure by the central and local governments on goods and services. It can be broadly classified into recurrent expenditure and capital expenditure. The capital expenditure refers to the amount of expenditure is used in the purchase of productive assets such as roads, ports, machinery, plant and equipment. On the other hand, the recurrent expenditure is the expenditure on the consumable goods and services that the government uses from time to time such as salaries for public servants, purchase of inventories for day-to-day-use in the government and debt repayments (Economic Development Board, 2004). The capital expenditure by the government can create employment if the productive assets bought by the public spending authority are put to use in productive ways. If they are not put to use in more productive ways, they can turn down to slow employment growth because they are a reflection of unutilized assets because the government could have had more productive alternatives for using them. Also, it is worth noting that the use to which they are put cannot create employment immediate but there are lags. 
For instance, if the government builds roads, it will take time for the private sector investors to put money in the investments schemes (Fasano \& Goyal, 2009). Those schemes will be a creation of employment so that government expenditure as a determinant of employment would depend on the nature of the expenditure and the time lag effect of the employment creation by the government. The effect of government expenditure will depend on the manner and efficiency with which the expenditure is made. If the government invests in capital expenditure, it will boost the aggregate demand for supplies to the construction works and this will make it realize high levels of employment. However, if the expenditure is recurrent, it will limit the ability of its expenditure to create employment.

\section{Research Methodology}

\subsection{Research Model}

The following model will be estimated by the study:

$$
U n_{t}=\beta_{0}+\beta_{1} G D P_{t}+\beta_{2} F C F_{t}+\beta_{3} I_{t}+\beta_{4} G o v_{t}+\varepsilon_{t}
$$

$\beta_{0}=$ Intercept

$\beta_{i}=$ Coefficient of the variables of the study

$G D P=$ Economic growth

$U n_{t}=$ the rate of unemployment in Bahrain for each of the study years between 1980 and 2015.

$G D P_{t}=$ Gross Domestic Product

$F C F_{t}=$ Fixed capital Formation

$I N F_{t}=$ Inflation

$G X_{t}=$ Government Expenditure

$\varepsilon_{t}=$ the error term

In the model, the variables are explained as follows:

- Gross Domestic Product:Gross domestic product (GDP) refers to the money value of goods and services that are produced within the geographical boundaries of a country over a given period of time. It is measured by the GDP value as reported by the Bahrain Bureau of Statistics.

- Rate of Capital Formation: The rate of fixed capital formation refers to the change in the capital stock of a country over time for a country. The study will use the reported levels of capital for Bahrain for the period of the study. It will be measured by the growth of capital stock.

- Inflation: Inflation refers to the change in the general prices of goods and services over time in a given country. It will be measured by the reported consumer price indices in the World Bank Country Data.

- Government expenditure: This is the expenditure by the government on the purchases of goods and services.

The study made use of time series data to enable the analysis of the data and to answer the research objectives. The decision to use the time series data was because unemployment is a variable that keeps changing over years in response to the policy measures that the government makes from time to time. Also, the changes are attributed the economic environmental change that the economy is undergoing. Thus, it was essential that the modeled of the research be based on time series analysis.

Part of data on variables to be used in this study is observed and recorded over the period 1980-2015. Regression analysis based on the time series data implicitly assumes that the underlying time series are stationarity so that the classical t- statistic and F- statistic are used to test hypotheses (Gujarati, 2004).

However, most economic time series data often exhibit strong trends and the regression of one time series on one or more time series variables can give nonsensical or spurious results. In such a situation, a null hypothesis which should not be rejected can actually be rejected (Greene, 2008). Such spurious regression is avoided if the time series involved are all stationarity or if they are non-stationarity but cointegrated. Therefore, stationarity and Cointergration tests will be conducted on the time series used in the study in order to guard against spurious results. 


\subsubsection{Stationarity of Data}

Each time series was tested for the presence of a unit root, using the formal statistical tests to detect non stationarity. First, the Augmented Dickey Fuller (ADF) test procedures as explained by Dickey and Fuller (1979) and Mackinnon (1991) was used. The ADF test for unit root in a time series y, involved estimating the equation:

$$
\Delta y_{t}=\gamma+\tau t+\rho y_{t-1}+\sum_{i=1}^{\rho} \aleph \Delta y_{t-1}+v_{t}
$$

Where: $\gamma=$ drift (intercept), $\mathrm{t}$ is trend, $\mathrm{i}=$ the number of lags in $\Delta \mathrm{y}_{\mathrm{t}-\mathrm{i}}$ with the maximum being $\mathrm{p}$ and $\mathrm{v}$ is the random error term. The null hypothesis tested was: $H o: \rho=0$ against the alternative, $H a: \rho<0$. Failure to reject the null hypothesis implies that the time series variable contained a unit root and was therefore nonstationarity, otherwise it was stationarity. The null hypothesis will be rejected if the absolute value of the computed test statistic exceeds the Mackinnon's critical tau $(\tau)$ values at 5 per cent level of significance. However, if the absolute value of the computed test statistic was less than the critical value, the null hypothesis would not be rejected and it will be concluded that the time series is non-stationarity (Gujarati, 2004; Greene, 2008).

Each time series was tested for the presence of a unit root, using the formal statistical tests to detect non stationarity. First, the Augmented Dickey Fuller (ADF) test procedures as explained by Dickey and Fuller (1979) and Mackinnon (1991) was used.

Table 4.1: Stationarity Test Results

\begin{tabular}{|c|c|c|c|c|c|}
\hline Factor & t-statistic & t-critical & Probability & Lag period & $\begin{array}{c}\text { Stability } \\
\text { Degree }\end{array}$ \\
\hline Unemployment rate & 4.025 & 3.515 & 0.003 & 1 & $1^{\text {st }}$ \\
\hline Economic growth & 4.591 & 3.515 & 0.002 & 1 & $1^{\text {st }}$ \\
\hline Capital Formation & 4.258 & 3.515 & 0.002 & 1 & $1^{\text {st }}$ \\
\hline Government spending & 5.608 & 3.515 & 0.003 & 1 & $1^{\text {st }}$ \\
\hline Inflation & 4.976 & 3.515 & 0.002 & 1 & $1^{\text {st }}$ \\
\hline
\end{tabular}

The results for stationarity analysis are shown in Table 4.1. Under the Augmented Dickey Fuller time series stationarity test, the null hypothesis that unit root is present is tested against the alternative hypothesis that unit root is not present. The null hypothesis for the presence of a unit root in the time series for Unemployment rate, Economic growth, Capital Formation, Government spending, and Inflation could not be rejected at level. This is because the absolute values of the computed ADF statistics were less than the Mackinnon's critical values for the rejection of the null hypothesis at 10 per cent level of significance (Greene, 2008). Upon first lagging, all the five time series became stationarity indicating that they are all integrated of order 1.

\subsubsection{Heteroskedasticity}

A basic requirement in classical normal linear regression is that the error of regression must be normally distributed, with a mean of zero and constant variance (Gujarati, 2004; Christiaan et al., 2004; Greene, 2008). To ascertain normality, and to rule out heteroskedasticity and autocorrelation in the residual distribution, residual based tests will be performed on the residual series obtained from each of the response equations. The conclusion will be based on the probability of the Jarque-Bera statistic from the histogram-normality test. If it will be greater that the threshold 0.05 , the normality assumption of the regression residuals will be made and conclusion will be drawn that regression residuals, from all the estimated equations, followed a normal distribution.

\subsubsection{Autocorrelation}

The presence of autocorrelation will tested for each response equation using the Breusch-Godfrey (BG) langrage multiplier test for serial correlation. The statistical package used in estimating the output response equations, Eviews, routinely reported the Durbin-Watson (DW) statistic alongside other statistical estimates. The DW statistic developed by Durbin and Watson (1951) will be computed based on the estimated residuals and it assumes values ranging from 0 to 4 with a value 2 representing a case of no autocorrelation. The nearer the statistic is to the extreme values, 0 or 4 , the greater the evidence for autocorrelation (Gujarati, 2004). The decision as to whether the time series is auto correlated will be made based on the observed DW statistic. 


\subsubsection{Multicollinearity}

Linear correlation occurs when there is a linear relationship between the explanatory variables, or the presence of a strong correlation between the explanatory variables, and is the result of the trend of economic changers together over time, as this will increase the standard error (SE) in the estimated parameters, and thus a statistical tstatistic impaired and become the estimated parameters were not significant, and can be confirmed by lack presence of a linear correlation between the explanatory using test variables (VIF), where this test indicates that a high degree of correlation between the explanatory variables will lead to a rise in the value of the coefficient of determination $\left(\mathrm{R}^{\wedge} 2>0.9\right)$ where this value in the case of full linear correlation equal to one.

It can be inferred on this issue after calculating the value (VIF), If (VIF>5), this indicates a problem with a linear correlation after this test, the results were as shown in the table. It can be inferred on this issue after calculating the value (VIF), If (VIF>5), this indicates a problem with a linear correlation after this test, the results were as shown in the table.

The presence of high correlation between regressors will be tested on the basis of the significance of the correlation coefficients of the repressors as suggested by Farrar and Glauber (1967). However, to determine whether multicollinearity is really a problem, models will be constructed based on all the regressors and the equations estimated will be passed through a battery of statistical tests and assessed on the basis of their adjusted $\mathrm{R}$-squared and the number of insignificant t-ratios.

Table 4.2: VIF test results

\begin{tabular}{|l|c|}
\hline \multicolumn{1}{|c|}{ Dependent Variable } & VIF \\
\hline Economic growth & 2.156 \\
\hline Capital Formation & 1.936 \\
\hline Government spending & 3.591 \\
\hline Inflation & 2.051 \\
\hline
\end{tabular}

\subsection{Findings and Analysis}

After making sure that there is no statistic problems in variables, this research used the software of (Eviews 8) for estimation the model, as per shown in the below table:

Table 4.3: Study Model Regression Output

\begin{tabular}{|l|c|c|c|}
\hline \multicolumn{1}{|c|}{ Variables } & Coefficient & t-statistics & Prob. \\
\hline intercept & -0.06 & -0.52 & 0.517 \\
\hline Economic growth & -6.83 & -1.68 & 0.091 \\
\hline Capital Formation & -5.45 & -3.15 & 0.002 \\
\hline Government spending & -7.51 & -7.81 & 0.001 \\
\hline Inflation & 0.02 & 1.21 & 0.110 \\
\hline R - Squared & \multicolumn{3}{|c|}{0.76} \\
\hline Adjusted R - Squared & \multicolumn{3}{|c|}{0.75} \\
\hline F - Statistic & 42.5 \\
\hline Prob. (F-statistic) & \multicolumn{3}{|c|}{0.001} \\
\hline
\end{tabular}

Table 4.3 shows the regression output for estimated study model. It gives the variables of study (economic growth, fixed capital formation, government spending, and inflation), their beta coefficients, t-statistics, and the probability values. The economic growth is negatively related to the unemployment in Bahrain and has insignificant impact on unemployment in Bahrain. This is consistent with theory in which it is postulated that when the economy grows, more and more labor units of inputs are required to take part in the production. From the theory of labor, labor demand is a derived demand. This implies that the demand for labor as a production input depends on the level of economic activity of the country (Herbener, 2011). When the national income increases, firms respond by increasing the supply of goods and services to reap from the income rise and the increased purchasing potential. As this happens, more labor units are demanded so as to take part in the production of the increased product demands. Thus, at any given time, it is expected that when the GDP of a country increases, more employment opportunities are created. Thus, GDP and unemployment are negatively related (Herbener, 2011). 
The probability value of 0.091 implies that the coefficient of economic growth is significant at percent. The coefficient of fixed capital formation in the regression model is -5.45 which shows that it has a negative relationship with the rate of unemployment in the country. The magnitude of 5.45 implies that a percentage increase in the rate of fixed capital formation in the economy would result into a 5.45 percent reduction in the rate of unemployment in Bahrain. The level of significance of -0.02 shows that the beta coefficient is significant at 1 percent. These findings are in agreement with a number of studies which found a negative relationship between the two variables. Forder (2010) for instance argued that the changes in capital stock over a given period can be due to depreciation of the existing capital stock, disposals of existing stock, and replenishments of stock. Thus, the rate of capital formation differs from the previous period's stocks by the net change in capital stock (Forder, 2010). According to the study, positive changes in the capital stock are good for the economy since capital is an essential input component in production. However, the positivity of the contribution to employment would depend on a number of things (Forder, 2010). First, it would depend on the stage of production of the firm. At low levels of capital stock, an additional unit of capital stock to the existing stock would generate higher productivity than at higher levels of capital (Forder, 2010). Secondly, there is a differential in returns to capital depending on the sector of the economy. However, holding all these factors constant, a quick rate of capital formation is good for the economy because it engages more labor and thus increase it would decrease unemployment. These findings are thus confirmed by the findings of the study.

The coefficient for the government expenditure is -7.51 which also shows a negative relationship between it and unemployment rate and shows that the government expenditure has a significant impact on unemployment in Bahrain. The implication of the magnitude and sign of the coefficient is that a percentage increase in the government expenditure would result into 7.51 percent decrease in unemployment and vice versa. The p-value of 0.111 however rules out the significance of this relationship thus we can conclude that there is no significant relationship between the two variables. These results are consistent with many researches which state that the use to which the government spends determines the unemployment outcomes. If the government spends on investment activities in the country which compete with the private sector, it may crowd out the private sector and thus lead to decreased levels of employment. On the other hand, if the expenditure is done on complementary services to private sector production, the results would be that more jobs are created. On the other hand, the outcomes of expenditure by the government may depend on the sources of expenditure funds. For instance, if the expenditure is financed from tax revenues, the government can have the effect of discouraging savings and thus cut done on employment creation through the saving deposits in the commercial banks.

The capital expenditure by the government can create employment if the productive assets bought by the public spending authority are put to use in productive ways. If they are not put to use in more productive ways, they can turn down to slow employment growth because they are a reflection of unutilized assets because the government could have had more productive alternatives for using them. Also, it is worth noting that the use to which they are put cannot create employment immediate but there are lags. For instance, if the government builds roads, it will take time for the private sector investors to put money in the investments schemes (Fasano \& Goyal, 2009). Those schemes will be a creation of employment so that government expenditure as a determinant of employment would depend on the nature of the expenditure and the time lag effect of the employment creation by the government.

As for inflation, the results of benchmark analysis, it has reached the decline of inflation rate coefficient (0.02). This means that whenever the rate of inflation increased by $1 \%$ will lead to increased unemployment rate of $0.0027 \%$, but (insignificant) in the case of other independent variables held constant, and vary this result with the theory economic conditions in the inverse relationship between inflation rate and the unemployment rate according to Phillips curve, so that the relationship inversion between the two did not prove absolutely in all countries despite its presence in the case of developed countries, but in the case of developing countries, the relationship be between the inflation rate and the unemployment rate a positive because of the existence of a state of stagflation (stagflation) experienced by developing countries. Thus, this result does not agree with the fourth hypothesis that assumes (an inverse relationship between the rate of inflation and the rate of unemployment in Bahrain).The adjusted R-squared of 0.76 shows that the estimated model explains about 76 percent of the variations in the unemployment rate in Bahrain. The remaining 24 percent is explained by factors other than those estimated in the model. The overall significance of the model is shown by the F-statistic which is 42.5 . The critical value for the F-statistic is 5 per cent or 10 per cent depending on the researcher's choice of the level of significance. Regardless, the value of 42.5 is greater than either 5 percent or 10 percent. It thus implies that the overall model is significant and can thus be relied on in predicting the variations in the unemployment in Bahrain. 


\section{Conclusion}

\subsection{Unemployment and Economic Growth}

The study findings in chapter 4 of this study show that there is a significant relationship between economic growth and unemployment rate in Bahrain. Actually, the two are negatively related which implies that an increase in the rate of economic growth would translate into a reduction in the level of unemployment. This is a strong indicator of the dire requirement by the government to pursue strong policies to promote economic growth (Khadaroo, 2002). Among these policies are those of adoption of technology to ensure that the firms in the country can go beyond the production frontiers and produce more efficiently. The findings of this study are consistent with the growth theories discussed. From the theory of labor, labor demand is a derived demand (Khadaroo, 2002). This implies that the demand for labor as a production input depends on the level of economic activity of the country (Herbener, 2011).

When the national income increases, firms respond by increasing the supply of goods and services to reap from the income rise and the increased purchasing potential. As this occurs, more labor units are demanded so as to take part in the production of the increased product demands. Thus, at any given time, it is expected that when the GDP of a country increases, more employment opportunities are created (Lucas, 1990). Thus, GDP and unemployment are negatively related (Herbener, 2011). Other policies to promote employment through pursuing economic growth policies include the employee training which would ensure that the country at any one time has sufficient pool of employees to take part in the production process. The government should also ensure that the economy is open to trade to external world to promote trade through increasing export demand which enhance growth of the economy (Kay, 2009). It is also important hat all the growth policies as suggested in the literature be pursued including promoting basic and intermediate level education among and pursuing policies to attract foreign direct investment (Kay, 2009). All these would ensure that there is a flow to capital by enhancing economic growth which is an important channel through which employment can be promoted.

\subsection{Unemployment and Fixed rate of Capital Formation}

The study in chapter four estimated the way unemployment rate in Bahrain is affected by the rate of fixed capital formation. This variable was defined as the growth rate of the capital stock of the country at any one time. From theory, this is squarely a growth variable and it is thus a channel through which economic growth affects unemployment. The beta coefficient of the fixed rate of capital formation was found to be negative which implies that the two variables are negatively related. The findings were found to be consistent with the findings of Forder (2010) in which it is argued that the changes in capital stock over a given period can be due to depreciation of the existing capital stock, disposals of existing stock, and replenishments of stock. Thus, the rate of capital formation differs from the previous period's stocks by the net change in capital stock (Forder, 2010). According to the study, positive changes in the capital stock are good for the economy since capital is an essential input component in production.

\subsection{Unemployment and Government Expenditure}

Government expenditure can be on a number of items. These include recurrent expenditure and on capital expenditure. When the government spends more into the economy, it increases money flow into the economy whose significance on the macroeconomic outcomes would depend on the nature of aggregate demand at the time (Arrow, 2012). When the aggregate demand in the economy is high, then the additional money flow into the economy can meet the demand and thus cure the shortage.

However, it can increase the general price levels which would in turn become counterproductive because it would increase inflation. However, for this study, the effect of the government expenditure on the unemployment rate is found to be negative which shows that an increase in government spending would translate into a decrease in the rate of unemployment in the country (Arrow, 2012). The results are consistent with many researches which found that the effectiveness of government depends on the use to which the funds are put (Arrow, 2012). If the government expenditure is on investment activities in the country which compete with the private sector, the result would be that of crowding out the private sector and thus lead to decreased levels of employment. On the other hand, if the expenditure is made on the services that are complementary to private sector production, the outcomes would be that more jobs being created (Arrow, 2012). On the other hand, the outcomes of expenditure by the government may depend on the sources of expenditure funds. 
For instance, if the expenditure is financed from tax revenues, the government can have the effect of discouraging savings and thus cut done on employment creation through the saving deposits in the commercial banks.

\section{Recommendations}

First, the government should relax trade barriers between in and its global counterparts (Clague, Keefer, Knack, \& Olson., 2009). This will result into increased flow of goods and services and capital in and out of the economy. As this continues, the government will realize increased growth in revenues from international trade and thus improve the balance of payments (Clague, Keefer, Knack, \& Olson., 2009). This will lead to an increase in the arte of capital accumulation and thus growth in the economy. As the economy grows, more and more people will be engaged to take part in the increased need for production and this will generate more and more employment in the economy (Clague, Keefer, Knack, \& Olson., 2009).

Secondly, the government should promote private sector activities through the provision of subsidies and other incentives (Choe \& Ranks, 2013). When the government provides incentives to the private sector, the cost of production decrease and the relevant profit margin of the firms increase. This in turn makes the final product prices increase and this makes the private sector not to pursue labor input substitution policies in production (Choe \& Ranks, 2013). When the costs of production increase, the private sector producers will be inclined to pursue labor input substitution polices such outsourcing production function to cheaper labor services overseas or through increasing the capital-labor ratio in the production (Choe \& Ranks, 2013). Thus, the government should increase its private sector incentivizing to ensure that the undesirable production decisions are not made by the private sector.

Thirdly, the government should ease the restrictions on the capital movements into and out of the countries (Jerome \& Jacobs, 2006). Instead, capital movements should be allowed to be based on the nature of the market outcomes and forces of demand and supply. As capital continues to flow in response to interest rate differentials across the globe, domestic capital handling firms such as foreign exchange dealers, commercial banks and other dealers will improve toward efficiency and this will make them get more and more competitive through learning and exposure to the way other global partners carry out their practices (Jerome \& Jacobs, 2006). This way, they will realize efficiency improvement and in turn create more and more jobs as they continue to benefit from the efficiency gains.

\section{References}

Abedin, L. (2008). Enabling The Disabled In The UAE Labor Market. The Center for LaborResearch \& Information, Policy Research Paper No. 7, Dubai.

Abudahesh et al. . (2014). Potential Output, Total Factor Productivity and Institutions in the Private Sector of Saudi Arabia. Journal of Development and Economic Policies: Vol. 6, No.2.

Arrow, K. (2012). The Economic Implications of Learning by Doing. Review of Economic Studies 29, 661-69.

Assaad, R. F.-H. (2011). The Determinants of Employment Status in Egypt. FCND Discussion Paper No. 88 .

Bockerman, P., \& Ilmakunnas, P. (2009). Unemployment and self-assessed health: evidence from panel data. Health Economics. 18 (2), 161-179.

Bogdan, B. (2014). Returns to Education, Sectoral Pay Differentials and Determinants in Kuwait. Economics of Education Review, Vol. 8 (3): 263-276.

Boyce, C. J., Wood, A. M., \& Brown, G. D. (2012). The dark side of conscientiousness: Conscientious people experience greater drops in life satisfaction following unemployment. Journal of Research in Personality. 44 (4), 535-539.

Choe, J., \& Ranks, H. (2013). Do Foreign Direct Investment and Gross Domestic Investment promote economic growth? . Review of Development Economics, 7(1) , 44-57.

Clague, C., Keefer, P., Knack, S., \& Olson., M. (2009). Contract Intensive Money. Munich Personal RePEc Archive, 1-42.

Dufwenberg and Kirchsteiger . (2000). Reciprocity and wage undercutting. European Economic Review 44, 1069-1078. 
Economic Development Board. (2004). Reforming Bahrain's Labor Market. Summary of Workshop Presentations September 23, 24. (EDB): Bahrain.

Eita, J. H. (2011). Determinants of unemployment in India. International Journal of Business and Management, Volume 5(10), pp. 92-104

Fasano, \& Goyal. (2009). Emerging Strains in GCC Labor Markets. IMF WP/04/71, International Monetary Fund Washington D.C.

Forder, J. (2010). The historical place of the 'Friedman-Phelps' expectations critique. European Journal of the History of Economic Thought. 17 (3), 493-511.

Gordon, R. J. (2011). The History of the Phillips Curve: Consensus and Bifurcation. Economica. 78 (309), 10-50. Greene, W. (2008). Econometric analysis, 6th ed. . New Jersey: Pearson-Prentice Hall .

Gul, H. K. (2012). Revisiting of Philips Curve: A case study from Pakistan. International Journal of Business and Behavioral Sciences, Volume 2, No. 6, pp. 53-78.

Herbener, J. M. (2011). The Fallacy of the Phillips Curve". Dissent on Keynes: A Critical Appraisal of Keynesian Economics. New York: Praeger.

Hye, Q. M. (2011). Stability of Phillips Curve: Rolling Window Analysis in the case of Pakistan. World Applied Sciences Journal, Volume 9(6), pp. 699-703.

Jerome, O., \& Jacobs, K. (2006). Foreign Direct Investment in Nigeria. African Economic Research Consortium, 157-190.

Johansen, S. (1992). Cointegration in partial systems and the efficiency of single equation analysis. Journal of Econometrics, Volume 52, Issue 3, pp. 389-402., http://dx.doi.org/10.1016/0304-4076(92)90019-N.

Kalim, R. (2013). Population and unemployment: A dilemma to resolve. The IUP Journal of Applied Economics, Volume 2, Issue 3, pp. 7-15.

Kay, P. (2009). Impact of FDI on Economic Growth in Pakistan. Pakistani Journals of International Trade, 1-22.

Khadaroo, S. A. (2002). Impact of FDI on economic growth Sub-Sahara African Countries. African Management Journals , 1-18.

Kingdon, G. G. (2014). Race and the incidence of unemployment in South Asia. Review of Development Economics, Volume 8(2), pp. 198-222. http://dx.doi.org/10.1111/j.1467-9361.2004.00228.x.

Lagace, R., \& Goolsby, J. (2006). Scaling and measurement: A quasi-replicative assessment of revised version of INDSALES. Journal of Personal Selling \& Sales Management, 13(1), 65-72.

Lavinia Ştefania et al. (2014). Impact of Unemployment on Economic Growth in Romania: During Crisis. Academy of Economic Studies, Bucharest, Retrieved from:www.revistadestatistica.ro/wpcontent/uploads/2014/02/rrs_06_2013_a3en.pdf.

Layard, R. (2004). Good Jobs and Bad Jobs. London School of Economics, CEP Occasional Paper N0 19.

Lippman, S. A. (2012). The economics of job search: A survey. Economic Inquiry, Volume 14, Issue 2, pp. 155189. http://dx.doi.org/10.1111/j.1465-7295.1976.tb00386.x.

Lopez, R. (2015). Minimum Wage Surges in 2015 and Beyond. The National Law Review. , 12-23.

Lucas. (1990). Why Doesn't Capital Flow from Rich to Poor Countries. American Economic Review, 12-23.

Lyroudi, K., P. A., \& Vamvakidis, A. (2004). The Importance of FDI on Economic Growth: Evidence from Transition Economies. South- Eastern Europe Journal of Economics (1), 97-110.

Meier, G. (2014). Leading Issues in Economic Development 4th ed.

Monastiriotis, V. (2015). Macro-determinants of UK regional unemployment and the role of employment flexibility. EI Working Paper No. 2015-01.

Morada, H. (2002:1). Work and Work Conditions of the UAE Nationals: A Four-Sector Comparison. Center for Labor Market Research and Information (Tanmia), Dubai, 12-5.

Mortensen, D. T. (2012). Job search, the duration of unemployment, and the Phillips curve. The American Economic Review, Volume 60, No. 5, pp. 847-862. http://www.jstor.org/stable/1818285. 
Mortimer, R. (2012). Heterogeneous Capital, the Production Function and the Theory of Distribution. Review of Economic Studies. 37 (3), 407-436.

Nickell, S. (2014). Unemployment and labour market rigidities: Europe versus North America. The Journal of Economic Perspectives, Volume 11, No. 3, pp. 55-74. http://dx.doi.org/10.1257/jep.11.3.55.

Pesaran, M. H. (2014). An autoregressive distributed-lag modeling approach to cointegration analysis. Econometric Society Monographs, Volume 31, pp. 371-413.

Pesaran, M. H., Shin, Y., \& Smith, R. J. (2012). Bounds testing approaches to the analysis of level relationships. Journal of Applied Econometrics, Volume 16(3), pp. 289-326. http://dx.doi.org/10.1002/jae.616.

Schoeman, C. D. (2014). An investigation into the determinants of the South African unemployment rate 19702010. Acta Academica, Volume 40(3), pp. 67-84.

The World Bank. (2016). Unemployment, total (\% of total labor force) (modeled ILO estimate).

Valadkhani, A. (2012). The causes of unemployment in Bahrain: An empirical investigation. International Journal of Applied Business and Economic Research, Volume 1(1), pp. 21-33.

Vedder, R., \& Gallaway, L. (2011). Out of Work: Unemployment and Government in the Twentieth-Century America. New York: NYU Press.

Zaman, K. M. (2011). Inflation, Unemployment and the NAIRU in Pakistan (1975-2009). International Journal of Economics and Finance, Volume 3(1), pp. 245-254. 